\title{
Chronic Cerebrospinal Venous Insufficiency in Multiple Sclerosis: Fact or Fiction!? Comment on Dr. Jim Reeker's Reply
}

\author{
Djordje Radak $\cdot$ Nenad Ilijevski
}

Published online: 18 October 2011

(C) Springer Science+Business Media, LLC and the Cardiovascular and Interventional Radiological Society of Europe (CIRSE) 2011

We appreciate Dr. Reeker's creative instructions and understanding concerning the dilemma to treat or not to treat CCSVI in multiple sclerosis, under present condition of the health system in Serbia [1, 2]. Yet, such dilemma is not the only one that future randomized studies should elucidate, which we tried to emphasize in our letter as well!

If we waited for the completion of major randomized clinical trials, we would have been at risk that many MS patients would go abroad and get the procedure in centers that do not seem to share our concern about the validity of the procedure and its outcome. Therefore, we designed our own single-center prospective study to analyze early and late results (mean follow-up more than 1 year). Endovascular treatment was performed in 42 of 75 patients with MS in which CCSVI was detected by Duplex scanning and confirmed by CT angiography, which met the criteria to be included in the study [2]. The early and 1-year results are to be analyzed, and if found unsatisfactory, we will discontinue the procedure until the results from major trials become available.

Another issue that we wanted to stress, and that major studies also should take into consideration, is that obligatory CT angiography in more than $30 \%$ of MS patients revealed various external compression on the jugular vein.
If "jugular compressive syndrome" is the real fact, with solid hemodynamic implications, it could (1) additionally bring under questioning the concept of endovascular treatment of CCSVI in MS because PTA will not release the external compression; (2) lead to conclusion that Duplex scanning alone might be insufficient for CCSVI diagnosis, thus influencing the design of major randomized clinical trials that are still in preparation.

Conflicts of interest None.

\section{References}

1. Reekers J (2011) Reply to letter to the editor: chronic cerebrospinal venous insufficiency in multiple sclerosis: Fact or fiction? Cardiovasc Interv Radiol 2011. doi:10.1007/s00270-011-0239-2

2. Radak D, Kolar J, Sagic D, Antonic Z, Tanaskovic S, Babic S, Ilijevski N (2011) Chronic cerebrospinal venous insufficiency in multiple sclerosis-fact or fiction!? Cardiovasc Interv Radiol 2011. doi:10.1007/s00270-011-0238-3

D. Radak $\cdot$ N. Ilijevski $(\bowtie)$

Dedinje Cardiovascular Institute, School of Medicine,

Belgrade University, Vascular Surgery Clinic,

Milana Tepica 1, 11040 Belgrade, Serbia

e-mail: aleksili@sbb.rs 